\title{
Development of Spatio-Temporal Database Prototype for Management of 4-Dimensional Cadastre Objects In Indonesia
}

\author{
Miranty Noor Sulistyawati ${ }^{1}$, Trias Aditya ${ }^{2}$, Purnama Budi Santosa ${ }^{2}$ \\ ${ }_{1}^{1}$ Magister (S2) Teknik Geomatika Departemen Teknik Geodesi Fakultas Teknik UGM \\ 2 Departemen Teknik Geodesi Fakultas Teknik Universitas Gadjah Mada INDONESIA
}

\section{Article History:}

Received 8 December 2018

Received in revised form 12 December 2018

Accepted 14 Deember 2018

Available online 31 January 2019

\section{Keywords:}

Basisdata, riwayat, data spatio-temporal, kadaster, 4D, Versionedobject, LADM

Corresponding Author:

Miranty Noor Sulistyawati

Email: miranty.noor.s@mail.ugm.ac.id

\begin{abstract}
The dynamics of the Indonesian population has increased causing the need for cadastral objects to increase. $2 D$ and $3 D$ cadastral objects change over time. Cadastral objects have spatial and juridical data changes every day. These changes can be caused by the transfer of rights, changes of rights, split and merging cadastral objects. Changes are recorded and stored as a history of cadastral objects (4-dimensional cadastre). Historical data on cadastral objects can be categorized as one of the big data in the cadastre sector, based on the frequency of recording data. The data can be used to track changes in cadastral objects so that they can avoid disputes. Spatial data in this case is very vulnerable data to cause disputes if the shape, position and size do not match the conditions in the field, and need special attention in integrating with the juridical data. This paper aims to identify methods for storing spatial data of $4 D$ cadastral objects that are suitable for Indonesia. The importance of storing cadastral objects and their history causes researchers and cadastre experts in the world to formulate international standards in managing spatial and juridical data along with a history of cadastral objects ( $4 D$ cadastre). LADM is an international standard conceptual model (ISO 19152) which can show the legacy of a cadastral object expressed in RRR (Rights, Restriction and Responsibility). In LADM, there is a VersionedObject class that represents various versions or a history of spatial units, object registration, owner and administration. Several studies conducted by researchers in the world were compared in this paper to find methods for applying LADM and VersionedObject classes. That methods were implemented in this paper to design a database of spatio-temporal $4 D$ cadastre. Finally a prototype of spatial-temporal database will be produced to manage 4D cadastral objects..
\end{abstract}

(C) Author(s) 2018. This is an open access article under the Creative Commons Attribution-ShareAlike 4.0 International License (CC BY-SA 4.0).

\section{Pendahuluan}

Döner et al., (2010) menyatakan bahwa sifat objek kadaster itu dinamis sama seperti dunia yang selalu berubah, selalu akan ada perubahan dari waktu ke waktu baik dari sisi bentuk maupun peralihan hak. Perubahan yang terjadi tidak hanya pada objek 2D tetapi juga pada objek 3D, yang dikenal dengan objek kadaster 4D (objek kadaster 3D + versi temporal/waktu).

FIG (2014) menyatakan bahwa dibutuhkan sebuah konsep untuk dapat mengatur administrasi objek kadaster 2D/3D beserta riwayatnya (kadaster 4D). Maka dirumuskan sebuah konsep Kadaster 2014. Hal yang dikaji pada Kadaster 2014 meliputi lima paket pokok, yaitu: (1) Subyek pemilik, (2) Penentuan, pembatasan dan keandalan informasi pertanahan (RRR-Rights, Restriction and Responsibility), (3) Objek teregistrasi (BA Unit), (4) Unit spasial (geometri bidang tanah), serta (5) Referensi spasial (surveying) dan penyajian data geospasial pertanahan.

Kelima paket pada konsep Kadaster 2014 agar mudah diterapkan dalam sistem informasi pertanahan maka disajikan dalam bentuk diagram konseptual berbasis objek (UML) yang disebut dengan LADM. Land Administration Domain Model (LADM) adalah model konseptual berstandar internasional (ISO 19152, 2012) yang dapat 
menunjukkan hubungan kelegalan suatu objek kadaster yang dinyatakan dalam RRR (Rights, Restriction and Responsibility) (FIG, 2014). Budisusanto, Aditya, \& Muryamto (2013) dalam penelitiannya menyatakan bahwa kelima kelas utama dalam LADM dapat diterapkan dalam sistem administrasi pertanahanan ruang $3 \mathrm{D}$ di Indonesia sesuai dengan peraturan yang berlaku, yaitu UU no.20 Tahun 2011 tentang Rumah Susun dan Peraturan Kepala BPN RI no.1 Tahun 2010 tentang Standar Pelayanan dan Pengaturan Pertanahan.

Data pencatatan riwayat objek kadaster merupakan salah satu big data dalam bidang pertanahan. Frekuensi pencatatan yang sangat sering dan beragam perlu dikelola dengan efektif dan efisien agar mudah ditelusuri di kemudian hari. Saat ini di berbagai negara telah banyak dikembangkan sistem pengelolaan informasi objek kadaster yang dapat mengelola objek kadaster 2D/3D beserta riwayatnya (kadaster 4D). Pengelolaan riwayat objek kadaster pun telah diakomodasi oleh LADM dalam kelas VersionedObject. Kelas VersionedObject ditambahkan pada LADM untuk mengelola dan memelihara data historis dalam basisdata. Kelas VersionedObject memiliki atribut riwayat pertanahan, meliputi begin validity version date (tanggal mulai berlaku data) dan end validity version date (tanggal berakhirnya data). Namun, belum banyak peneliti memfokuskan dan menerapkan kelas VersionedObject ini dalam sistem informasi pertanahan yang mereka kembangkan.

Di Indonesia telah dilakukan penelitian terkait implementasi kelas VersionedObject LADM dalam mengelola objek kadaster beserta riwayatnya. Sucaya (2009) melakukan penelitian untuk menerapkan konsep LADM pada sistem kadaster di Indonesia. Semua kelas pada diagram UML LADM diimplementasikan pada data pertanahan di Indonesia yang disimpan dalam basisdata PostgreSQL dan diimport ke dalam mesin peta MapServer. Salah satu kelas pada LADM yang diteliti oleh Sucaya (2009) adalah VersionedObject. Pada penelitian tersebut diberikan contoh pencarian riwayat perubahan hak suatu bidang tanah dengan menggunakan bahasa SQL yang hasilnya ditampilkan pada QGIS seperti pada Gambar 1.1. Tabel hasil pencarian tersebut menunjukkan isi dari kelas VersionedObject pada LADM, karena berhasil menghubungkan antara objek parties (nama pemegang hak), administrasi (transaksi, hak, waktu validitas hak) dan spatial units yang ditunjukkan oleh nomor bidang yang sama tetapi memiliki waktu validitas hak yang berbeda. Penelitian ini saat ini telah dikembangkan menjadi Sistem Informasi Pertanahan Nasional Indonesia, yang dikenal dengan Komputerisasi Kantor Pertanahan (KKP). Namun, pada penelitian yang telah dilakukan (Sucaya, 2009), objek kadaster yang dikelola hanya bidang tanah 2D dan belum dapat mengelola objek kadaster 3D.

Paper ini bertujuan untuk mengidentifikasi metode implementasi kelas Versionedobject LADM dalam mengelola objek kadaster 4D (rumah susun). Metode pengelolaan objek kadaster 4D yang telah diidentifikasi tersebut diwujudkan dalam sebuah prototype basisdata spatio-temporal. Pada basisdata yang dibuat ditambahkan atribut waktu agar dapat menyimpan riwayat perubahan objek kadaster, baik pada data spasial maupun tekstual. Untuk menunjukkan riwayat objek kadaster baik 2D maupun 3D dapat ditambahkan data atribut tmax dan tmin pada kelas LADM yang dinamis, yaitu pemilik (parties), RRR, registrasi objek. Data atribut tmax dan tmin ini pada prinsipnya hampir sama dengan atribut begin validity version date (tanggal mulai berlaku) dan end validity version date (tanggal berakhirnya hak) yang tercantum pada kelas VersionedObject LADM (Oosterom, Ploeger, Stoter, Thompson, \& Lemmen, 2006).

\section{Data dan Metodologi}

Metode komputerisasi dalam mengelola informasi pertanahan dapat mempercepat dan meningkatkan ketepatan pencatatan data, sehingga mengefektifkan serta mengefisienkan kegiatan terkait pengelolaan informasi pertanahan. Pengelolaan data berbasis komputer ini dapat memanfaatkan aplikasi basisdata spasial, antara lain PostgreSQL atau Oracle. LADM dan kelas VersionedObject dapat diterapkan dalam perancangan basisdata spasial untuk dapat mengelola data kadaster 4D. Pada ISO 19152 (2012) telah tercantum desain pengelolaan administrasi pertanahan beberapa negara, salah satunya Indonesia. Desain pengelolaan administrasi pertanahan setiap negara tersebut disebut juga Country Profile LADM. Desain Country Profile dibuat dalam diagram berbasis objek (UML). Pada desain tersebut sudah ditambahkan kelas VersionedObject untuk mengelola riwayat setiap kelas. Desain Country Profile Indonesia pada ISO 19152 dapat diimplementasikan dan dijadikan acuan dasar perancangan basisdata spatio-temporal untuk mengelola objek kadaster 4D.

\begin{tabular}{|c|c|c|c|c|c|c|c|c|}
\hline & $\begin{array}{l}\text { transactiontype } \\
\text { character(20) }\end{array}$ & $\begin{array}{l}\text { type } \\
\text { character(20) }\end{array}$ & $\begin{array}{l}\text { beginvalidityversion } \\
\text { date }\end{array}$ & $\begin{array}{l}\text { endvalidityversion } \\
\text { date }\end{array}$ & $\begin{array}{l}\text { remark } \\
\text { character(11) }\end{array}$ & $\begin{array}{l}\text { name } \\
\text { character varying(100) }\end{array}$ & $\begin{array}{l}\text { identity } \\
\text { character(14) }\end{array}$ & $\begin{array}{l}\text { number } \\
\text { character varying(100) }\end{array}$ \\
\hline 1 & Pendaftaran Pertam & Hak Milik & $1966-09-21$ & $1977-04-13$ & Person & CLARA SALAMONG & 09010303.06193 & 09010303.1 .523 \\
\hline 2 & Ganti Nama & Hak Milik & $1977-04-13$ & 1977-11-03 & Person & LISEETH CLARA SALMON MATHIAS & 09010303.06193 & 05010303.1 .523 \\
\hline 3 & Pewarisan & Hak Milik & 1977-11-03 & 1977-11-04 & GroupPerson & KELUARGA MATHIAS & 09010303.06193 & 09010303.1 .523 \\
\hline 4 & Jual Beli & Hak Milik & 1977-11-04 & $1981-02-24$ & Person & HER/ HENRY & 09010303.06193 & 09010303.1 .523 \\
\hline 5 & Jual Beli & Hak Milik & 1981-02-24 & $2000-08-28$ & Person & TAURUK BIN RAHMAD HARLARAH & 09010303.06193 & 09010303.1 .523 \\
\hline
\end{tabular}

Gambar 1.1 Contoh tabel hasil pencarian riwayat perubahan hak (Sucaya, 2009) 


\subsection{Data dan Lokasi}

Data yang dijadikan studi kasus pada penelitian ini adalah salah satu rumah susun yang berlokasi di Kabupaten Sleman, Provinsi Yogyakarta, yaitu Rusunawa Gemawang. Lokasi Rusunawa Gemawang di citra satelit disajikan pada Gambar 2.1. Data yang dikumpulkan untuk penelitian ini berupa data primer dan data sekunder. Data primer tersebut adalah data koordinat pojok bangunan dan sampel titik unit satuan rumah susun. Data tersebut dikumpulkan dari hasil pengukuran lapangan Rusunawa Gemawang tahun 2015 yang dilakukan oleh Tim Peneliti Teknik Geodesi UGM (Heliani \& Widjadjanti, 2015).

Data sekunder dikumpulkan dari Pengelola Rusunawa Gemawang. Data sekunder tersebut meliputi denah desain Rusunawa Gemawang tahun 2009 dan tabel kepemilkan unit satuan rusunawa (data tekstual).

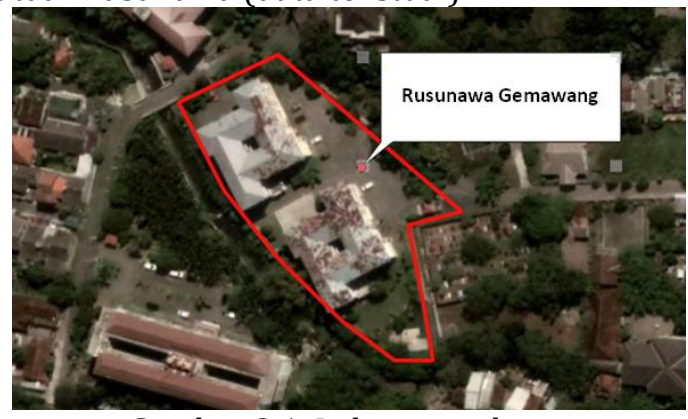

Gambar 2.1 Lokasi penelitian

\subsection{Pemrosesan Data}

Pada pemrosesan data terdapat 3 kegiatan utama meliputi digitalisasi data spasial, digitalisasi data tekstual dan konversi data spasial menjadi format GeoJSON. Tahap pertama yang dilakukan adalah mendigitalisasi data spasial hasil pengukuran lapangan. Data tersebut masih berupa data koordinat $(\mathrm{X}, \mathrm{Y}, \mathrm{Z})$, sehingga perlu dilakukan digitasi atau penggambaran secara digital. Objek kadaster 3D digambarkan dengan pendekatan hybrid dan format konstruksi.

Pendekatan hybird adalah metode penyajian objek kadaster 3D yang teregistrasi pada bidang tanah 2D (baik di atas maupun di bawah bidang tanah) (Stoter, Salzmann, \& Molen, 2002). Pendekatan hybird ini dianggap paling efisien baik dalam penyimpanan data dalam basisdata dan penyajian objek kadaster 3D. Format konstruksi dipilih karena bentuknya yang sederhana.
Proses digitasi/penggambaran dilakukan dengan menggunakan perangkat lunak AutoCAD Map 3D. Penggambaran objek kadaster 3D tersebut menggunakan koordinat lapangan dan dan acuan bentuk dari set plan rusunawa. Rusunawa digambarkan dalam sistem koordinat TM-30 (untuk wilayah Kabupaten Sleman digunakan sistem koordinat DGN'95 TM $3^{0}$ zona 49.1).

Setiap unit rusun diberi kode unik untuk memudahkan identifikasi setiap ruang. Seluruh unit rusun disamakan memiliki 6 sisi. Kemudian masing-masing sisi tersebut disimpan dalam file AutoCAD yang berbeda untuk memudahkan masukan data dalam basisdata.

Tahap kedua dalam pemrosesan data adalah digitalisasi data tekstual. Data tesktual yang diperlukan dalam penelitian ini adalah kepemilikan unit satuan rusunawa dan riwayat pergantiannya. Namun, data kepemilikan tersebut dalam bentuk cetak dan hanya dicatat pada sebuah buku, sehingga didigitalisasi. Seluruh informasi kepemilikan unit satuan rusun didigitalisasi dan disimpan dalam format MS.Excel (*.CSV).

Setelah semua data spasial dan tekstual terdigitalisasi, maka tahap ketiga yang perlu dilakukan dalam pemrosesan data adalah mempersiapkan data spasial agar siap dimasukkan dalam basisdata spasial. Pada tahap sebelumnya, data spasial tersimpan dalam format AutoCAD (CAD). Format ini tidak bisa langsung dimasukkan dalam basisdata, sehingga perlu dikonversi dulu menjadi format Well Known Text (WKT) yang dipahami oleh aplikasi basisdata spasial. Format data WKT yang digunakan dalam penelitian ini adalah GeoJSON. Page (2015) menyebutkan bahwa GeoJSON merupakan format data WKT yang dibuat dalam bahasa pemrograman Javascript, dan file Javascript dikenal memang berukuran kecil dan ringan untuk diproses.

Proses konversi data CAD setiap sisi ruang/komponen menjadi data GeoJSON dilakukan dengan menggunakan tools ogr2ogr GDAL, seperti yang disajikan pada Gambar 2.2.2. Pada proses konversi dipilih format data yang diinginkan (GeoJSON), selain itu dilakukan pemilihan format geometri (Multipolygon Z). Pada tahap ini juga dilakukan transformasi dari sistem proyeksi DGN'95 TM3 ${ }^{0}$ (satuan meter) menjadi sistem proyeksi geografik WGS'84 (satuan derajat desimal). Hal ini dilakukan agar data koordinat yang akan tersimpan dalam basisdata bersifat global dan sesuai disajikan pada library peta apapun.

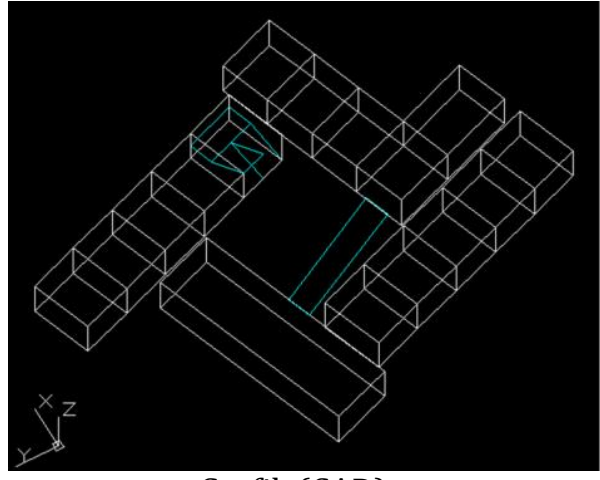

Grafik (CAD)

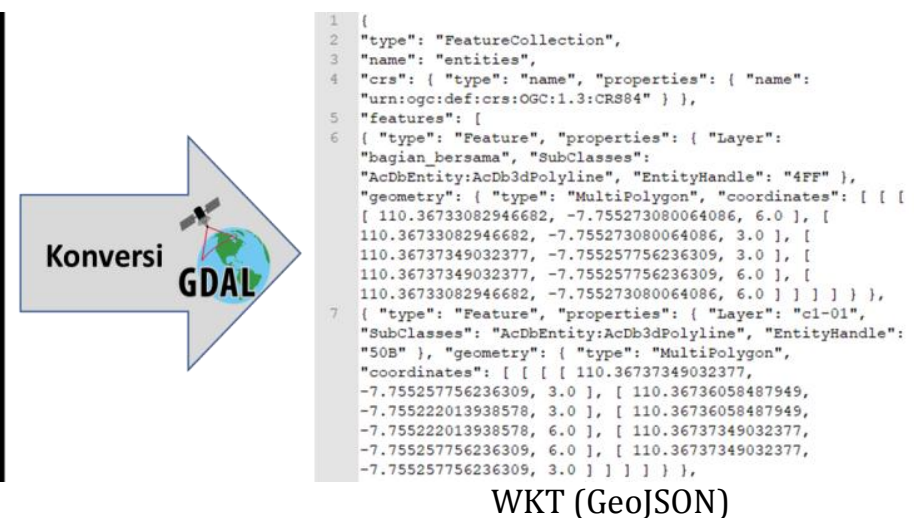

WKT (GeoJSON)

Gambar 2.2 Konversi grafik (CAD) menjadi WKT (GeoJSON) 


\subsection{Perancangan Basisdata Spatio-Temporal}

Pada tahap ini dilakukan perancangan basisdata spatiotemporal untuk mengelola data kadaster 4D. Desain basisdata yang dibuat mengacu kepada Country Profile LADM Indonesia dan hasil penelitian yang telah dilakukan oleh Oosterom, Ploeger, et al., (2006). Pada Gambar2.3 disajikan UML Country Profile LADM Indonesia. Pada UML tersebut disajikan model administrasi yang telah disesuaikan dengan sistem administrasi di Indonesia antara lain pada jenis hak yang diakomodasi. Jenis hak kadaster 2D (hak milik, hak pakai, hak guna bangunan dan lainnya) serta hak kadaster 3D (HMSRS) coba diakomodasi pada model Country Profile tersebut. Diharapkan model ini dapat dikembangkan dan dijadikan acuan dalam membuat desain basisdata spatio-temporal.
Namun pada model Country Profile LADM Indonesia tersebut belum disebutkan secara rinci mengenai implementasi kelas VersionedObject. Di sisi lain, telah dilakukan penelitian mendetil terkait implementasi kelas VersionedObject pada basisdata kadaster (Oosterom, Lemmen, et al., 2006). Pada penelitian tersebut diperoleh salah satu kesimpulan bahwa untuk menerapkan kelas VersionedObject dalam basisdata kadaster, dapat dilakukan dengan menambahkan atribut tmin (waktu penambahan data) dan tmax (waktu habis berlakukanya data), seperti pada Gambar2.4.

Berdasarkan penjelasan di atas, maka paper ini menerapkan kedua hal tersebut. Desain basisdata pada paper ini mengacu kepada Country Profile LADM Indonesia dan menambahkan atribut tmin dan tmax pada beberapa kelas (hak, BAunit/registrasi objek, unit spasial).

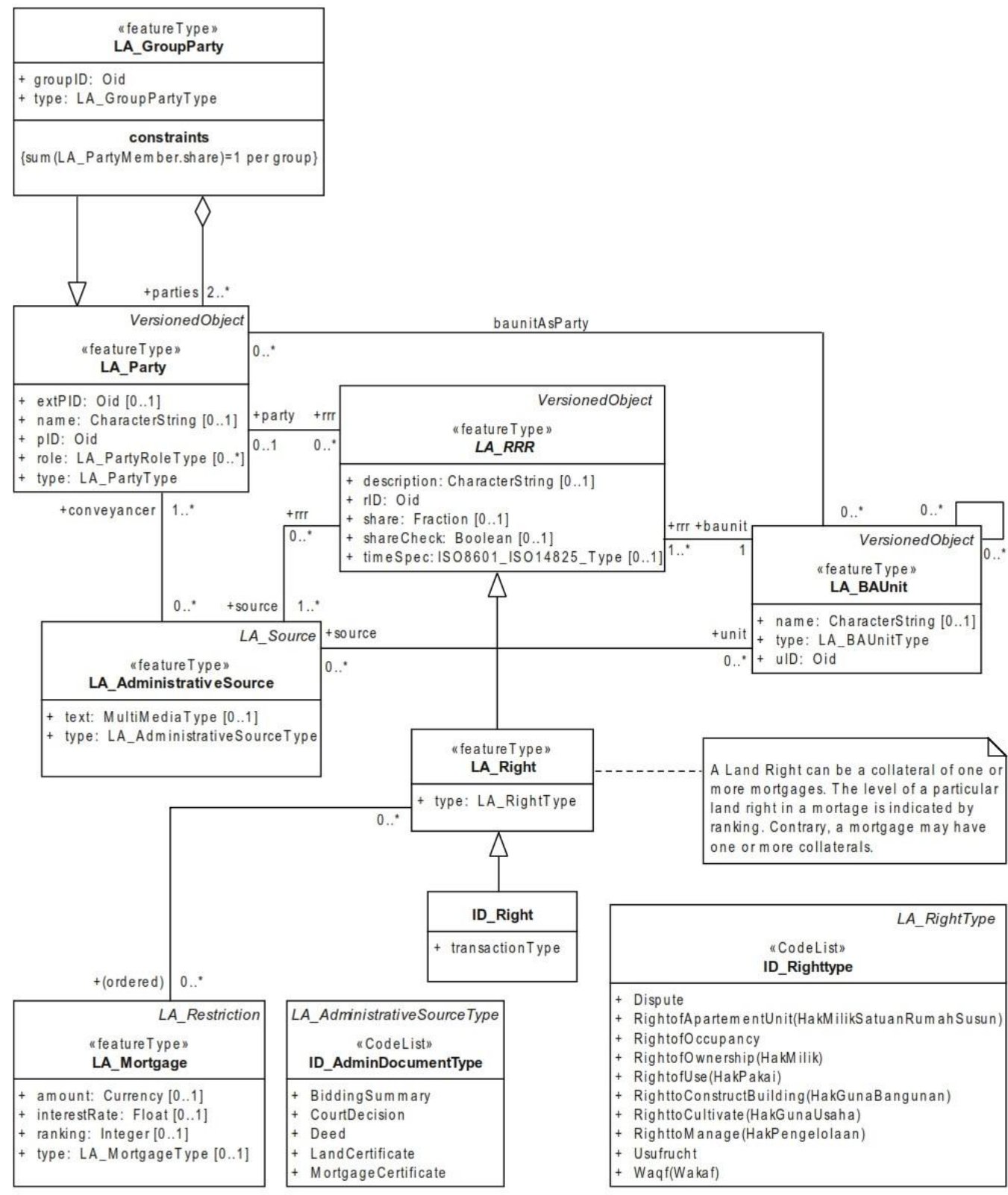

Gambar2.3 Country Profile LADM Indonesia (ISO 19152, 2012) 


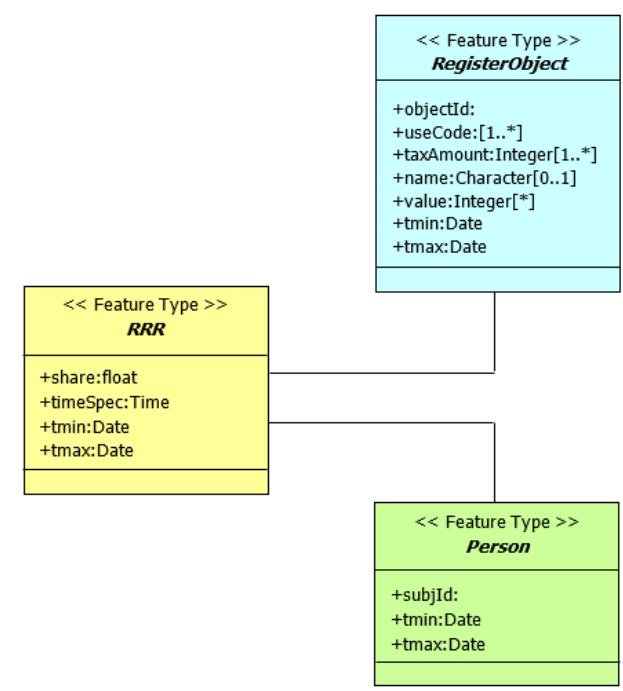

Gambar 2.4 Penambahan atribut tmax dan tmin pada UML LADM

\subsection{Pembuatan Prototype Basisdata Spatio-Temporal}

Pembuatan prototype basisdata spatio-temporal kadaster 4D dilakukan pada perangkat lunak PostgreSQL berekstensi PostGIS. Perangkat lunak basisdata tersebut dipilih karena sifatnya yang opensource dan dapat diperoleh secara gratis. Selain itu, PostgreSQL merupakan aplikasi basisdata yang dapat dikembangkan dengan bahasa pemrograman apapun.

Terdapat 21 tabel yang dibuat pada basisdata dengan mengacu pada Country Profile LADM Indonesia. Tabel tersebut disajikan pada Gambar2.5. Dua puluh satu tabel tersebut telah meliputi 5 paket pokok LADM. Dengan rincian sebagai berikut :

- Kepemilikan (parties) : IDN_party, IDN_groupparty, jenis_party, status_kepemilikan_hak.

- $\quad$ RRR terutama Rights (hak) : IDN_rights, jenis_rights, registrasi_hak2D, registrasi_hak3D, dokumen.

- BAUnit (registrasi objek) : IDN_baunit_2d, IDN_baunit3d.

- Unit spasial : IDN_spaces, IDN_parcel, IDN_stratatitle, IDN_commonequipment, IDN_3d_spatial, jenis_commonequipment.

- Surveying and Representation: IDN_face.

Tabel dalam basisdata tersebut terdiri dari kolomkolom atribut, baik spasial maupun tekstual. Selain itu juga terdapat atribut waktu yang menunjukkan waktu berlakunya sebuah data. Penambahan atribut waktu ini mengacu pada penelitian yang dilakukan oleh (Oosterom, Ploeger, et al., 2006). Contoh penambahan atribut waktu pada beberapa tabel disajikan pada Gambar2.6. Pada beberapa tabel yang memiliki riwayat perubahan (seperti hak, BA Unit dan unit spasial) ditambahkan minimal 2 atribut waktu, yaitu t_add/t_start (waktu penambahan data) dan t_end (waktu habisnya masa berlaku sebuah data). Kedua atribut waktu ini dapat digunakan untuk memantau aktivasi dan validitas berlakukanya suatu data. Apabila sudah melewati t_end maka suatu data pertanahan tersebut seharusnya sudah tidak berlaku lagi (tidak aktif/mati).

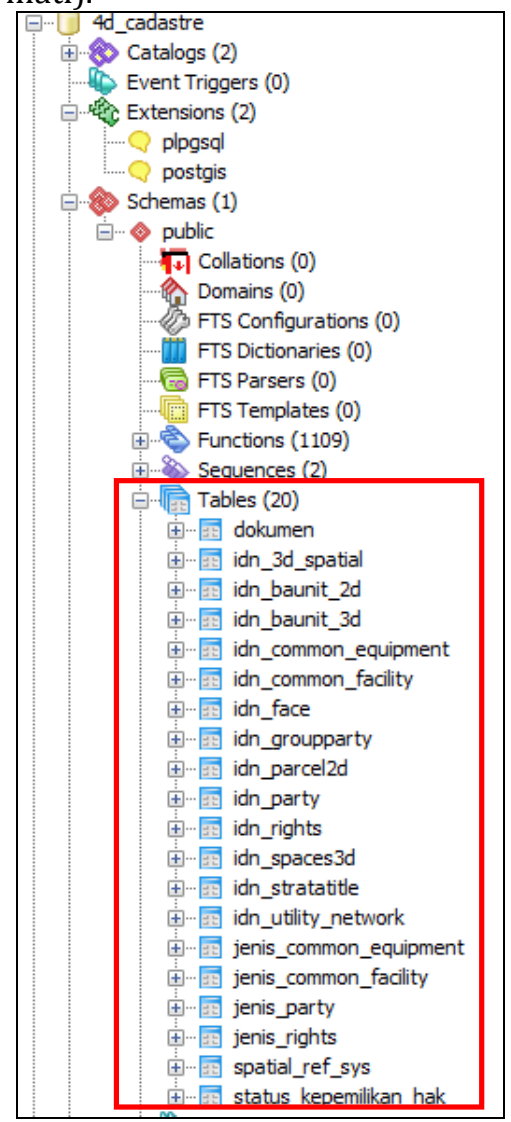

Gambar 2.5 Tabel dalam basisdata
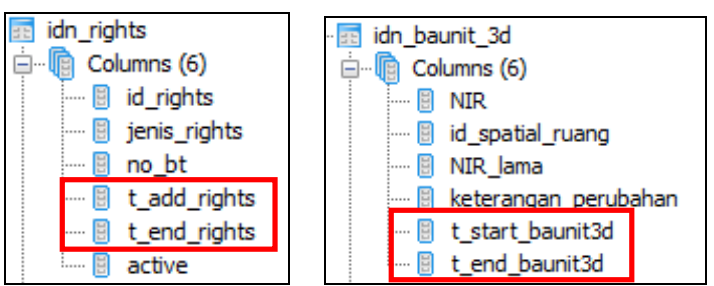

Gambar 2.6 Contoh tabel yang memiliki atribut waktu

Selain struktur tabel dan kolom pada basisdata, hal lain yang perlu diperhatikan dalam pembuatan basisdata adalah metode pemasukan dan keluaran data. Data masukan dan keluaran pada basisdata berupa data spasial dan atribut.

Data masukan spasial yang telah disiapkan berupa data WKT GeoJSON. Pada file GeoJSON, geometri objek kadaster 2D dan 3D dituliskan dalam bentuk koordinat (WKT). Supaya dapat dimasukkan dalam basisdata diperlukan beberapa fungsi untuk merubah geometri berformat WKT menjadi format Well Known Binary (WKB). Proses pemasukan data WKT GeoJSON disajikan pada Gambar 2.2.7. Pada gambar tersebut ditunjukkan bahwa data WKT GeoJSON perlu dilakukan konversi dulu menjadi data WKB dengan fungsi SQL ST_GeomFromGeoJSON. Setelah itu data WKB tersebut dimasukkan ke dalam basisdata pada kolom geometri, dengan fungsi INSERT. Kedua fungsi tersebut dapat dieksekusi pada satu query SQL. 


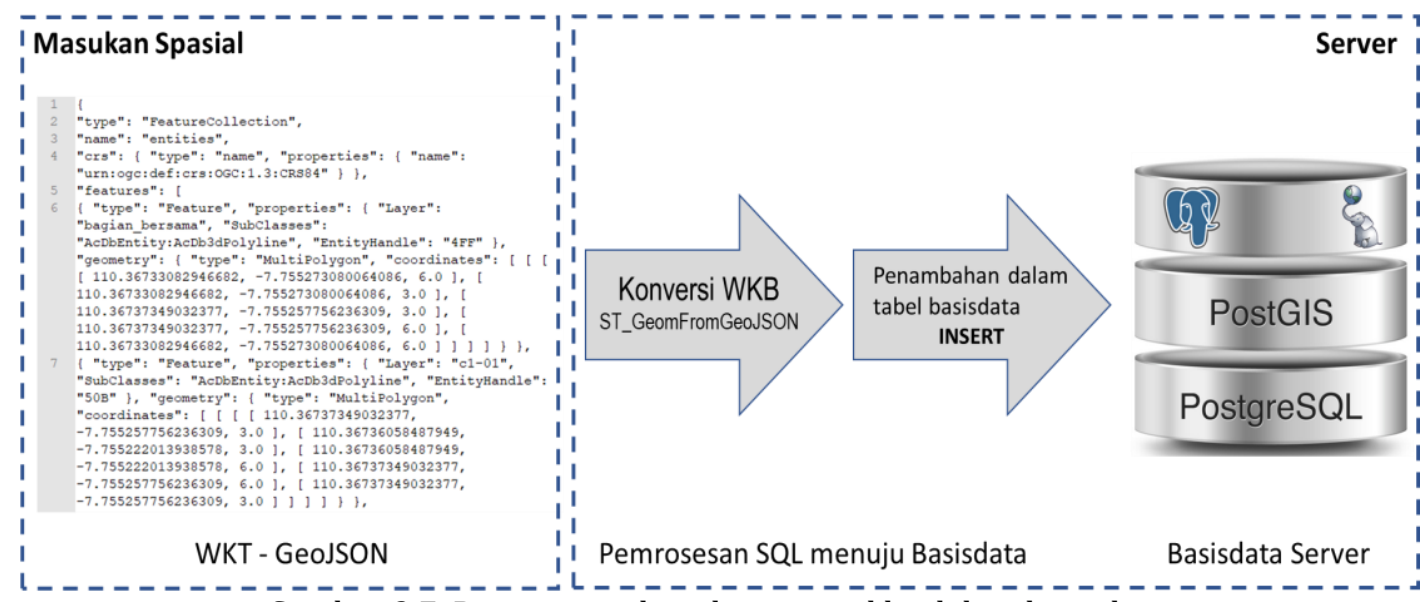

Gambar 2.7 Proses masukan data spasial ke dalam basisdata

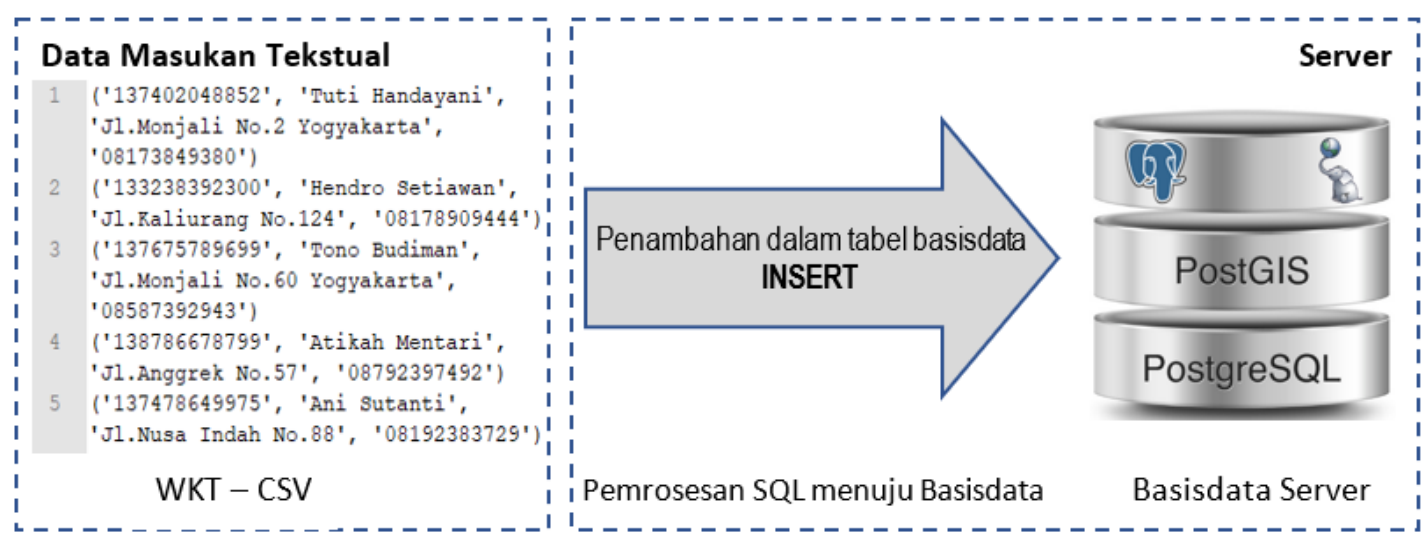

Gambar 2.8 Proses masukan data tekstual ke dalam basisdata

Setiap data spasial yang dimasukkan dalam basisdata dibedakan berdasarkan jenisnya, dengan rincian sebagai berikut :

- Data spasial sisi unit ruang masuk dalam tabel idn_face.

- Data spasial bagian bersama masuk dalam tabel idn_commonfacility.

- Data spasial benda bersama masuk dalam tabel idn_commonequipment.

Data masukan tekstual juga telah disiapkan dalam format WKT, namun berbentuk file CSV. Proses penambahan data tekstual ke dalam basisdata disajikan pada Gambar 2.8. Penulisan pada data WKT CSV sudah sesuai dengan syntax SQL penambahan data tekstual pada basisdata. Sehingga sesuai dengan yang ditunjukkan Gambar 2.8, data WKT CSV cukup disalin pada jendela query SQL dan ditambahkan fungsi INSERT pada masingmasing baris data.

Sama seperti data spasial, data tekstual yang dimasukkan pun dibedakan tabelnya berdasarkan jenis data yang diinput. Rincian masukan dalam tabel tekstual sebagai berikut :
- Data tekstual pemilik masuk dalam tabel idn_party

- Data tekstual registrasi kepemilikan hak masuk dalam tabel registrasi_kepemilikan_hak

- Data tekstual registrasi status hak pada objek kadaster masuk dalam tabel idn_rights

- Data tekstual objek teregistrasi beserta riwayat perubahan objek masuk dalam tabel idn_baunit_2d dan idn_baunit_3d

- Data tekstual informasi rumah susun/apartemen masuk dalam tabel idn_stratatitle

- Dan seterusnya.

Pada basisdata spatio-temporal terdapat bagian penting pada penambahan data riwayat berseri (VersionedObject) terutama untuk data spasial. Penyimpanan data riwayat berserti dilakukan dengan cara menyimpan informasi NIR/NIB sebelumnya atau asal dan juga menambahkan atribut waktu (t_start dan t_end) pada tabel BAUnit. Seperti yang disajikan pada Gambar 2.9, informasi perubahan yang terjadi pada suatu objek kadaster dapat ditelusuri dan disajikan hanya melalui asal NIR dan waktu berlakunya.

\begin{tabular}{|c|c|c|c|c|c|}
\hline & $\begin{array}{l}\text { nir } \\
\text { character varying(80) }\end{array}$ & $\begin{array}{l}\text { nir_asal } \\
\text { character varying(80) }\end{array}$ & $\begin{array}{l}\text { t_start } \\
\text { date }\end{array}$ & $\begin{array}{l}\text { t_end } \\
\text { date }\end{array}$ & $\begin{array}{l}\text { geom } \\
\text { text }\end{array}$ \\
\hline 1 & 11.01 .12 .01 .09 .00087 & & 2010-10-09 & $2012-07-14$ & MULTIPOLYGON Z $(((110.367330829467-7.755273080064099,11)$ \\
\hline 2 & 11.01 .12 .01 .09 .00180 & 11.01 .12 .01 .09 .00087 & $2012-07-14$ & 2015-09-10 & MULTIPOLYGON Z $(((110.367330829467-7.75527308006409$ 9,11) \\
\hline 3 & 11.01 .12 .01 .09 .00766 & 11.01 .12 .01 .09 .00180 & $2015-09-10$ & 2017-04-19 & MULTIPOLYGON Z $(((110.367330829467-7.75527308006409 \mathrm{9,11}$ \\
\hline 4 & 11.01 .12 .01 .09 .00900 & 11.01 .12 .01 .09 .00766 & 2017-04-19 & & MULTIPOLYGON Z $(((110.367330829467-7.755273080064099,11)$ \\
\hline
\end{tabular}

Gambar 2.9 Pencatatan nomor identitas asal dan waktu berlaku untuk menelusuri riwayat objek kadaster 


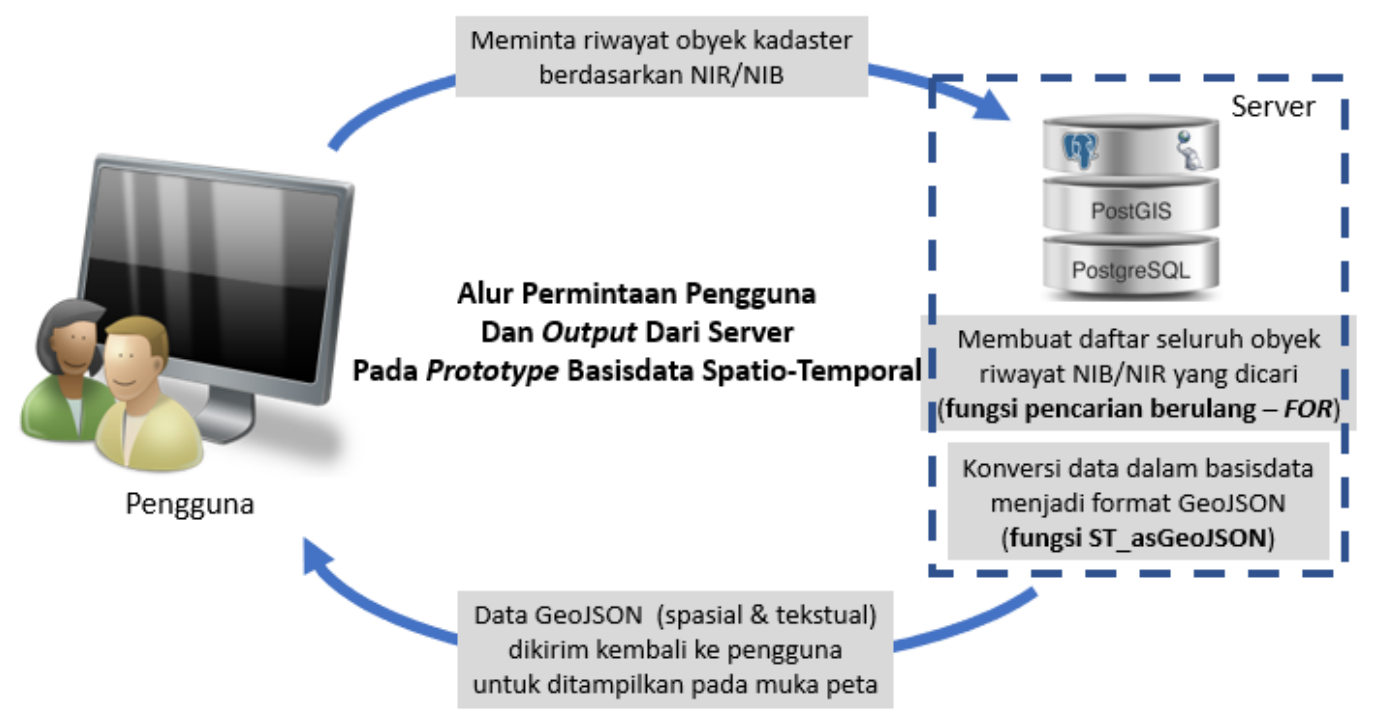

Gambar 2.10 Alur permintaan pengguna dan data keluaran dari server

Setelah semua data penelitian dimasukkan dalam basisdata, perlu dipikirkan metode pemrosesan keluaran data agar dapat memenuhi permintaan pengguna. Pada aplikasi kadaster spasio-temporal, pengguna diperkirakan akan melakukan permintaan untuk dapat menyajikan perubahan objek kadaster 4D secara spasial pada dekstop mereka. Pengguna membutuhkan kriteria objek untuk melakukan permintaan. Kriteria ini dapat berupa nomor identitas (NIR/NIB). Permintaan NIR/NIB pengguna akan dikirimkan ke basisdata di server. Sistem pada server akan mencari data riwayat NIR yang diminta pengguna pada basisdata. Pencarian ini dilakukan dengan memanfaatkan fungsi FOR. Hasil pencarian/query selanjutnya disimpan pada tabel semetara, jika pada basisdata PostgreSQL disebut dengan view. Hasil pencarian dibuat dalam daftar pada view, sehingga dapat lebih tertata dan tidak mengacak data lainnya. Agar dapat dikirim ke pengguna dan disajikan pada dekstop mereka dengan ringan maka data dalam view perlu dirubah ke dalam format WKT GeoJSON. Perubahan data ini memanfaatkan fungsi SQL ST_asGeoJSON. Data WKT GeoJSON yang dihasilkan kemudian dikirim ke pengguna untuk selanjutnya diproses pada dekstop mereka untuk ditampilkan. Gambaran proses keluaran data mulai dari permintaan sampai pengiriman data kepada pengguna disajikan pada Gambar 2.10.

\section{Hasil dan Pembahasan}

Penelitian pada paper ini menghasilkan dua produk utama, yaitu desain basisdata (UML) dan prototype basisdata spatio-temporal untuk pengelolaan objek kadaster 4D. Pada bab metodologi telah dijelaskan bahwa pembuatan prototype basisdata spatio-temporal beracuan dari Country Profile LADM Indonesia dan penelitian Oosterom, Ploeger, et al., (2006). Pada Gambar 3.1 disajikan UML desain basisdata spatio-temporal untuk objek kadaster 4D yang telah disesuaikan dengan sistem administrasi pertanahan di Indonesia.

Pada beberapa kelas pada UML tersebut dapat dilihat bahwa sudah ditambahkan atribut t_start dan t_end agar dapat mengakomodasi implementasi kelas VersionedObject. Pada paket Parties, kelas VersionedObject diterapkan pada kelas IDN_Party. Pada kelas IDN_Party diperlukan pencatatan waktu untuk menunjukkan riwayat perubahan pemilik pada sebuah kegiatan administrasi. Penerapan kelas VersionedObject pada kelas IDN_party ditandai dengan adanya atribut t_start_party dan t_end_party.

Pada paket Administrasi, kelas Versionedobject diterapkan pada kelas IDN_Right. Pada kelas IDN_Right diperlukan pencatatan waktu untuk menunjukkan riwayat perubahan hak pada sebuah kegiatan administrasi. Penerapan kelas VersionedObject pada kelas IDN_right ditandai dengan adanya atribut t_start_hak dan t_end_hak. Perubahan hak dapat terjadi karena hilang/rusaknya sertipikat, atau bisa juga dikarenakan perubahan spasial objek kadaster (pemecahan, penggabungan, pemisahan).

Pada paket BAUnit, kelas VersionedObject diterapkan pada kelas IDN_3DBAUnit dan IDN_2DBAUnit. Pada kedua kelas tersebut perubahan yang terjadi adalah perubahan bentuk spasial teregistrasi baik untuk objek kadaster 2D maupun 3D. Riwayat perubahan objek teregistrasi selain dengan pencatatan waktu, dapat ditunjukkan dengan pencatatan NIR saat ini dan NIR sebelumnya (NIR dan NIR asal).

Pada paket SpatialUnit, kelas VersionedObject diterapkan pada semua kelas di dalam paket tersebut. Pencatatan objek spasial diperlukan untuk mengetahui waktu berlakunya sebuah objek spasial kadaster. Penerapan kelas VersionedObject pada paket SpatialUnit ditandai dengan adanya atribut t_start dan t_end. 
Salah satu hasil dari penelitian ini adalah desain basisdata spatio-temporal untuk kadater 4D. Selanjutnya UML yang dihasilkan dikomparasi dengan UML yang telah ada sebelumnya untuk mengetahui kelebihannya apabila kedua UML tersebut digabungkan, yaitu Country Profile Indonesia dan hasil penelitian Oosterom, Ploeger, et al., (2006). Pada Tabel 3.1 disajikan hasil komparasi implementasi kelas VersionedObject pada 3 UML administrasi pertanahan. Secara keseluruhan, ketiga tabel tersebut sama-sama telah menerapkan kelas VersionedObject. Namun Country Profile Indonesia belum dilengkapi tata cara penambahan informasi waktu dan data berseri. Paper Oosterom, Ploeger, et al., (2006) belum coba diimplementasikan pada sistem informasi Indonesia. Pada desain prototype basisdata spatio-temporal mengacu UML Country Profile Indonesia dan juga telah ditambahkan atribut waktu dan data berseri secara detail. Desain ini telah coba diterapkan dalam prototype basisdata spatiotemporal untuk mengelola data kadaster 4D di Indonesia, dan hasilnya desain ini berhasil diterapkan.

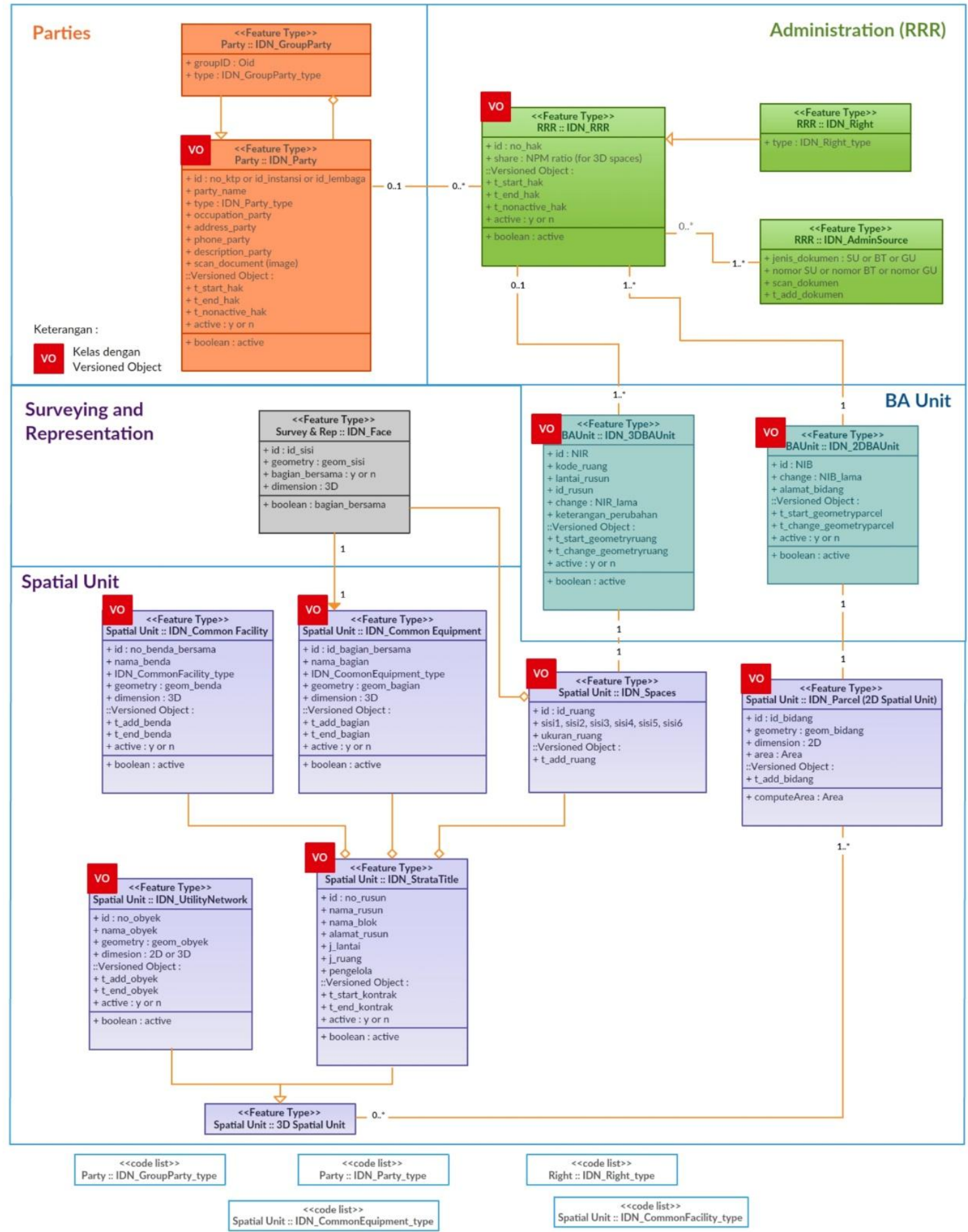

Gambar 3.1 UML desain prototype basisdata spatio-temporal kadaster 4D 
Tabel 3.1 Perbandingan implementasi kelas VersionedObject

\begin{tabular}{|c|c|c|c|c|}
\hline No. & Keterangan & $\begin{array}{c}\text { Paper } \\
\text { Oosterom, } \\
\text { Ploeger, et } \\
\text { al., (2006) }\end{array}$ & $\begin{array}{l}\text { Country } \\
\text { Profile } \\
\text { Indonesia }\end{array}$ & $\begin{array}{c}\text { Prototype } \\
\text { Basisdata } \\
\text { Spatio- } \\
\text { temporal } \\
\text { Kadaster 4D }\end{array}$ \\
\hline 1 & $\begin{array}{l}\text { Penerapan kelas } \\
\text { VersionedObject } \\
\text { pada rancangan } \\
\text { system }\end{array}$ & $\begin{array}{c}\text { YA } \\
\text { (ditambahkan } \\
\text { atribut t_max, } \\
\text { t_min) }\end{array}$ & $\begin{array}{c}\text { YA } \\
\text { (namun tidak } \\
\text { dijelaskan } \\
\text { secara detil } \\
\text { penambahan } \\
\text { atribut } \\
\text { waktunya dalam } \\
\text { UML) } \\
\end{array}$ & $\begin{array}{c}\text { YA } \\
\text { (t_start, t_end, } \\
\text { t_change, } \\
\text { boolean active } \\
\text { or not) }\end{array}$ \\
\hline 2 & $\begin{array}{l}\text { Kelas yang } \\
\text { ditambahkan } \\
\text { kelas } \\
\text { VersionedObject }\end{array}$ & $\begin{array}{l}\text { Party, Right, } \\
\text { RegisterObject } \\
\text { (BA Unit) }\end{array}$ & $\begin{array}{l}\text { Party, Right, } \\
\text { RegisterObject } \\
\text { (BAUnit) }\end{array}$ & $\begin{array}{l}\text { Party, Right, } \\
\text { RegisterObject } \\
\text { (BAUnit) 2D } \\
\text { dan 3D, } \\
\text { SpatialUnit 2D } \\
\text { dan 3D. } \\
\end{array}$ \\
\hline 3 & $\begin{array}{l}\text { Penambahan } \\
\text { informasi waktu } \\
\text { mulai dan } \\
\text { berakhirnya } \\
\text { sebuah data } \\
\text { dalam basisdata }\end{array}$ & YA & YA & YA \\
\hline 4 & $\begin{array}{l}\text { Dimensi spasial } \\
\text { objek kadaster } \\
\text { yang dikelola }\end{array}$ & 3D + waktu & 3D + waktu & 3D + waktu \\
\hline
\end{tabular}

Keberhasilan penerapan desain prototype basisdata spatio-temporal untuk mengelola objek kadaster 4D akan dijelaskan pada contoh dibawah ini. Sebagai contoh pengguna sistem melakukan permintaan untuk menampilkan riwayat spasial dan atribut dari NIR '11.01.12.01.09.00900'. Server akan menerima permintaan tersebut melakukan pencarian data berseri pada basisdata (syntax SQL dalam kotak merah). Proses pencarian data dan penataan riwayat disajikan pada Gambar3.2. Pada Gambar tersebut, sistem melakukan query SQL berdasarkan NIR dan asal NIR, kemudian ditambahkan atau dicatat dalam view riwayat_3d (syntax SQL dalam kotak biru).

Setelah pencarian berakhir maka seluruh data riwayat perubahan dari NIR '11.01.12.01.09.00900' tercatat dalam view riwayat_3d seperti pada Gambar 3.3. NIR '11.01.12.01.09.00900' saat pertama kali rumah susun dibangun memiliki NIR '11.01.12.01.09.00087' sejak tanggal 9 Oktober 2010. kemudian pada tanggal 14 Juli 2012 terjadi penggantian NIR (bisa karena perubahan spasial atau yuridis) menjadi NIR '11.01.12.01.09.00180'. Dan selanjutnya sampai akhirnya pada tanggal 19 April 2017 objek kadaster pada lokasi tersebut didaftarkan dengan NIR '11.01.12.01.09.00900' yang berlaku sampai saat ini.

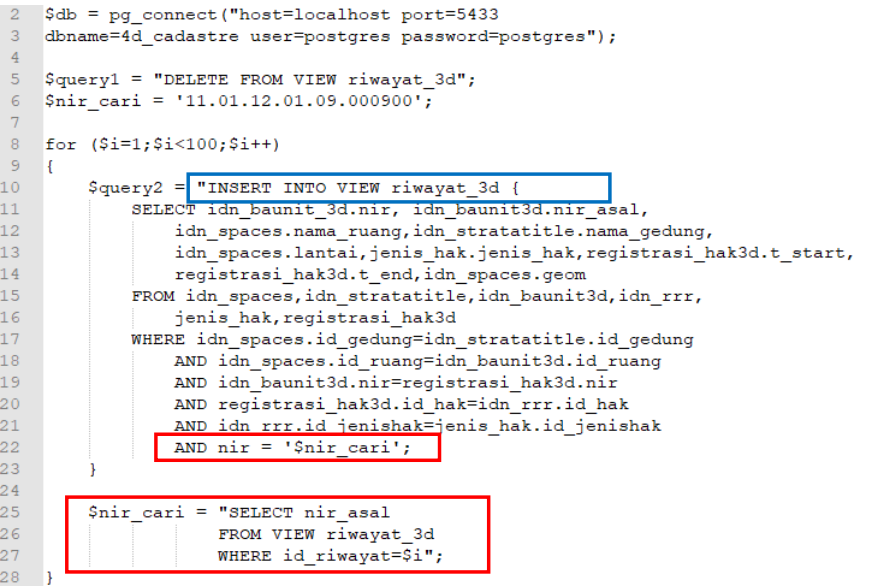

Gambar 3.2 Fungsi pencarian dan penelusuran riwayat objek kadaster pada prototype basisdata spatio-temporal (dengan syntax SQL)

\section{Kesimpulan}

Banyak peneliti telah melakukan penelitian untuk mengembangan model pengelolaan objek kadaster 4D, salah satunya Oosterom, Ploeger, et al., (2006). Pada penelitian tersebut mencetuskan penambahkan atribut t_max dan t_min untuk menunjukkan versi dari objek kadaster. Selain itu, pada ISO 19152 tecantum Country Profile skema aplikasi administrasi pertanahan untuk Indonesia. Kedua desain tersebut sudah coba dikembangkan pada paper ini. Pengembangan yang dilakukan pada paper ini adalah analisis percobaan penerapan penambahan atribut t_max dan t_min serta pencatatan asal objek untuk menjadi kunci penelusuran riwayat objek kadaster pada Country Profile LADM Indonesia (ISO 19152, 2012)

Hasil yang diperoleh pada paper ini adalah UML desain basisdata dan prototype basisdata spatio-temporal untuk mengelola data spasial dan tekstual objek kadaster 4D. Prototype basisdata spatio-temporal yang dihasilkan dapat digunakan untuk melakukan pengelolaan (masukan, manajemen dan keluaran data kadaster) serta penelusuran riwayat perubahan objek kadaster 3D baik spasial maupun tekstual. Pengguna dapat melakukan permintaan penelusuran riwayat suatu objek kadaster berdasarkan nomor identitas (NIR/NIB). Data riwayat suatu objek kadaster tersebut disajikan dalam sebuah daftar (pada view basisdata) sehingga memudahkan untuk pemrosesan selajutnya sampai data tersebut dapat disajikan pada dekstop pengguna. Desain dan prototype basisdata yang dihasilkan diharapkan dapat dijadikan sebagai masukan untuk pengembangan sistem informasi pertanahan Indonesia dalam mengelola riwayat objek kadaster, terutama objek kadaster 4D (objek kadaster 3D + riwayatnya).

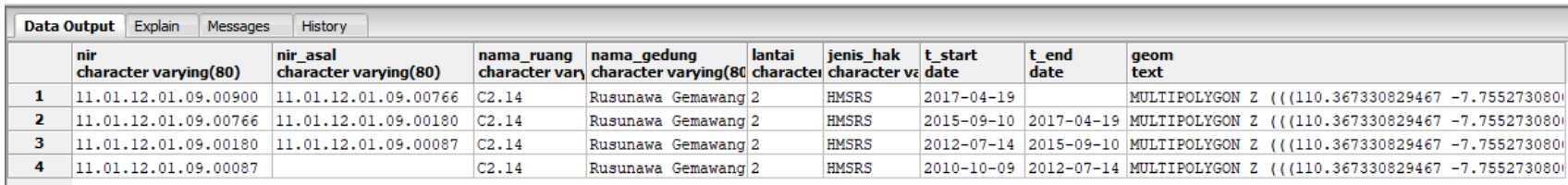

Gambar 3.3 Hasil query pencarian dan penelusuran riwayat objek kadaste 4D dengan NIR '11.01.12.01.09.00900' 


\section{Pernyataan Konflik Kepentingan}

Penulis menyatakan tidak ada konflik kepentingan dalam artikel ini (The authors declare no competing interest).

\section{Referensi}

Budisusanto, Y., Aditya, T., \& Muryamto, R. (2013). LADM Implementation Prototype for 3D Cadastre Information System of Multi-Level Apartment in Indonesia. Proceedings of 5th Land Administration Domain Model Workshop, (20), 456-475. Retrieved from http://www.gdmc.nl/3dcadastre/literature/3Dca d_2013_10.pdf

Döner, F., Thompson, R., Stoter, J., Lemmen, C., Ploeger, H., van Oosterom, P., \& Zlatanova, S. (2010). 4D cadastres: First analysis of legal, organizational, and technical impact-With a case study on utility networks. Land Use Policy, 27(4), 1068-1081. https://doi.org/10.1016/j.landusepol.2010.02.00 3

FIG. (2014). Cadastre 2014 and Beyond. Copenhagen: International Federation of Surveyor (FIG).

Heliani, L. S., \& Widjadjanti, N. (2015). Observation for 3D Mapping Research Excellence in UGM (Observation of GNSS on Each Apartment in Sleman Regency).

ISO 19152 - the Land Administration Domain Model. (2012). Oosterom, P. van, Lemmen, C., Ingvarsson, T., van der Molen, P., Ploeger, H., Quak, W., ... Zevenbergen, J. (2006). The core cadastral domain model. Computers, Environment and Urban Systems, 30(5), 627-660.

https://doi.org/10.1016/j.compenvurbsys.2005.1 2.002

Oosterom, P. Van, Ploeger, H., Stoter, J., Thompson, R., \& Lemmen, C. (2006). Aspects of a 4D Cadastre: A First Exploration, 1-23.

Page, R. (2015). Visualising Geophylogenies in Web Maps Using GeoJSON. PLoS Currents, 7.

Stoter, J. E., Salzmann, M. A., \& Molen, P. Van Der. (2002). Towards a 3D cadastre. Proceedings: FIG, ACSM ..., $1-12$.

Sucaya, A. (2009). Application and validation the land administration domain model in real life situation (a case study in Indonesia). Thesis, 92. 